\title{
TRATAMENTOS PRÉ-GERMINATIVOS EM SEMENTES FLORESTAIS DA AMAZÔNIA: VI - MUIRAJUBA Apuleia leiocarpa (VOG.) MACBRIDE VAR. molaris SPR. ex BENTH. (LEGUMINOSAE).
}

\author{
Luiz Augusto Gomes de SOUZA' Vania Palmeira VARELA ${ }^{2}$ Lucio Flavio \\ Pereira BATALHA ${ }^{2}$
}

\begin{abstract}
RESUMO - Com o objetivo de superar a dormência de sementes de muirajuba (Apuleia leiocarpa (Vog.) Macbride var. molaris Spr. ex Benth), foi conduzido um ensaio experimental com 12 tratamentos pré-germinativos: testemunha (sem tratamento); imersão em ácido sulfúrico concentrado $(96 \%)$ por diferentes períodos $(5,10,15,20$ e 30 minutos), imersão em água quente a $80^{\circ} \mathrm{C}$ ( 2 e 10 minutos); desponte do lado oposto ao hilo; escarificação manual por 2 minutos; e escarificação manual seguida por imersão em água (6 e 12 horas). A germinação foi realizada em germinador Jacobsen sob temperatura constante $\left(30^{\circ} \mathrm{C}\right)$, e acompanhada por 30 dias. Os efeitos dos tratamentos foram avaliados através da porcentagem de germinação e do Índice de Velocidade de Germinação (I.V.G.). Todos os tratamentos aplicados proporcionaram uma maior germinação em relação a testemunha, cuja germinação foi de somente $13 \%$. Porcentagens de germinação elevadas foram obtidas com as imersões em ácido sulfúrico, desponte do lado oposto ao hilo e escarificação manual por 2 minutos (com e sem imersão em água por 12 horas), os quais não diferiram entre sí. Dentre os tratamentos testados, o maior índice de vigor das sementes (I.V.G.) foi obtido com a escarificação manual por dois minutos, seguida por imersâo em água por 12 horas. Os tratamentos onde as sementes foram submetidas a água quente não foram eficientes para estimular a germinação das sementes de muirajuba.
\end{abstract}

Palavras-chave: Sementes, Dormência, Leguminosae, Apuleia.

Pre-Germination Ttreatments of Forest Seeds on Amazon Region: VI - Muirajuba Apuleia leiocarpa (Vog.) Macbride var molaris Spr. ex Benth. (Leguminisae).

ABSTRACT - A experimental study was conduced in order to overcome dormancy of muirajuba seeds (Apuleia leiocarpa (Vog.) Macbride var. molaris Spr. ex Benth), using 12 pre-germination treatments: the control treatment (without scarify); immersion in sulphuric acid concentrate $(96 \%)$ in different periods $\left(5,10,15,20\right.$ and 30 minutes); immersion in hot water at $80^{\circ} \mathrm{C}(2$ and 10 minutes); cutting-off the point on the opposite side of the hilar area, manual scarification for 2 minutes and manual scarification followed by immersion in water (6 and 12 hours). The germination was carried out in a Jacobsen germinator room at constant temperature $\left(30^{\circ} \mathrm{C}\right)$, and observed for 30 days. The treatments effects were evaluated through germination percentage and index ofgermination speed (I.V.G.). Every treatments applied provided a germination increase in comparation with the control treatment, whose germination was any $13 \%$. Increased in seed germination was obtained with immersion in sulphuric acid, cuttin-off in oposite side of hilar area, and manual scarification for 2 minutes (with or without immersion in water for 12 hours), have no different statistical. Among the treatments tested higher I.V.G. was obtained with manual scarification for 2 minutes followed by immersion in water for 12 hours. The treatments using hot water did not show any efficiency on germination of muirajuba seeds.

Key words: Seeds, Dormancy, Leguminosae, Apuleia.

1 Instituto Nacional de Pesquisas da Amazônia, INPA/CPCA. Caixa Postal 478, CEP 69.011970, Manaus, AM, Brasil.

2 INPA/CPST. 


\section{INTRODUÇÃO}

$\mathrm{O}$ aumento da percentagem de germinação, bem como sua aceleração e uniformidade, são os objetivos da quebra de dormência de sementes. Um grande número de essências florestais pertencentes à família das leguminosas apresentam sementes com tegumentos impermeáveis à água. Este tipo de dormência constitui um sério problema por ocasião da semeadura pela irregularidade na germinação afetando a homogeneidade das plântulas e o tempo de formação das mudas.

A ausência de resultados experimentais tem limitado a propagação de muitas espécies florestais de valor comercial existentes na Amazônia. A espécie muirajuba (Apuleia leiocarpa var. molaris) Leguminosae, Caesalpinioideae, tem ampla dispersão na América do Sul tropical (ALLEN \& ALLEN, 1981) em solos arenosos (FROES, 1959), e argilosos, nas matas de terra firme e na várzea alta, raro em solos inundáveis (LOUREIRO \& LISBOA, 1979; ALLEN \& ALLEN, 1981; SOUZA, 1987). Também ocorre em locais acidentados e colonizando capoeiras ensolaradas e áreas abandonadas (RIZZINI, 197I), e é conhecida em todo o Brasil por nomes como grapia, paucetim, amarelão, dentre outros.

A madeira da muirajuba possui múltiplos usos e é de excelente qualidade por suas propriedades mecânicas e durabilidade natural. É utilizada principalmente na construção civil externa e interna, marcenaria, tanoaria, cutelaria e como matéria prima para estacas, vigas, postes, tacos, dormentes, caibros, e outros (RIZZINI, 1971; RIZZINI \& MORS, 1976; LOUREIRO \& LISBOA, 1979; SUDAM/IPT, 1981; FREITAS \& CHIMELO, 1982; SOUZA, 1987). Mesmo sendo muito empregada regionalmente e apresentar amplo potencial, a madeira não tem sido exportada, por falta de conhecimentos de sua boas propriedades industriais entre os madeireiros.

Foram efetuados estudos de resistência ao apodrecimento e durabilidade de moirões de muirajuba (LELLES et al., 1978; FREITAS \& CHIMELO, 1982), sendo constatada boa resistência com ou sem o uso de preservativos. É espécie muito boa para produção de álcool, coque e carvão (PAULA, 1982). Testes com dormentes indicaram durabilidade de 12 anos em contacto com o solo, ou imersas em água (FREITAS \& CHIMELO, 1982). A regeneração natural foi estudada por LEITE \& HAY, (1989), que verificaram que a espécie apresenta baixa tolerância a sombreamento. A muirajuba também já foi investigada com relação a sua habilidade de nodular e fixar nitrogênio em simbiose com rizóbios, mas foi considerada não nodulífera (FARIA et al., 1984).

A espécie apresenta potencial para uso em sistemas agroflorestais, mas depende de informações silviculturais que facilitem o preparo, formação e homogeneidade das mudas. 
As sementes de muirajuba são duras e apresentam germinação natural lenta e irregular. Isto se deve à dormência das sementes, comum em algumas leguminosas, cujo tegumento é duro e impermeável à água (POPINIGIS, 1977). Quando a dormência está relacionada com a impermeabilidade das sementes, a germinação depende da degradação do tegumento que em condições naturais é realizada por microorganísmos o que permite a embebição do embrião, passo inicial de ativação dos processos metabólicos que atuam com a germinação.

MAGALHÃES et al., (1985), descreveram a germinação de sementes de 65 espécies nativas, no viveiro de produção de mudas para o banco de germoplasma de Tucuruí, no Pará, e observaram que a germinação média encontrada para a muirajuba, sem aplicação de tratamento escarificador, foi de $29,7 \%$, sendo a espécie considerada de baixo poder germinativo. TORRES (1983), efetuou testes preliminares de imersão em água quente ( 1 , 3 e 5 minutos) e água fria $(5,20$ e 40 horas), porém a maior germinação observada foi de $54,7 \%$ quando as sementes foram imersas 40 horas em água fria.

Este trabalho tem como objetivo identificar técnicas adequadas a superação da dormência de sementes da muirajuba, afim de estabelecer métodos para auxiliar o processo germinativo da espécie, tornando-o mais eficiente e uniforme.

\section{MATERIAL E MÉTODOS}

As sementes de muirajuba foram coletadas de uma única matriz em agosto de 1984, na área de inundação da
Hidroelétrica Tucuruí, a $300 \mathrm{~km}$ de Belém, no sul do estado do Pará, segundo a metodologia de coleta de germoplasma nativo aplicada por VENTURIERI et al. (1984). A matriz coletada encontrava-se em vegetação primária, descrita por REVILLA (1982), como Floresta alta homogênea de terra firme. A identificação taxonômica do material coletado foi efetuada pela Coordenação de Pesquisas em Botânica do INPA.

Durante a coleta foram feitas as seguintes observações sobre a árvore porta-sementes: circunferência à altura do peito (CAP): 2,20 metros; altura estimada da matriz: 30 metros; forma do fuste: cilíndrico torto; espessura da casca: 10 milímetros; forma do fruto: ovalada; e número de sementes por fruto: 1-3 sementes.

No período compreendido entre a coleta e a data da semeadura, as sementes foram armazenadas em sacos plásticos por 12 meses, em temperatura ambiente. Não foram observados ataques por pragas ou doenças durante o armazenamento. Por ocasião da instalação do ensaio as condições das sementes foram:

Peso de 1.000 sementes: 44 gramas. 22.727 .

Número de sementes por quilo:

Teor de umidade: $11,14 \%$.

Porcentagem de sementes flutuantes em água: $20 \%$.

Teste de corte: $100 \%$ viáveis.

O teste de umidade foi feito com três repetições de 10 sementes que fo- 
ram submetidas à secagem em estufa a $105^{\prime \prime} \mathrm{C}$ por 24 horas de exposição, com determinação das massas envolvidas antes e depois da secagem e cálculo da porcentagem de umidade. $O$ teste de corte foi feito com canivete de ponta afiada destruíndo-se a semente para avaliar sua sanidade interna, considerando-se sã aquela que não apresentava dano.

Os tratamentos testados para superar a dormência das sementes foram os seguintes:

T1 - Testemunha, sem aplicação de tratamentos escarificadores.

T2 - Imersão em ácido sulfúrico (96\%) por 5 minutos.

T3 - Imersão em ácido sulfúrico por 10 minutos.

T4 - Imersão em ácido sulfúrico por 15 minutos.

T5 - Imersão em ácido sulfúrico por 20 minutos.

T6 - Imersão em ácido sulfúrico por 30 minutos.

T7 - Imersão em água quente a $80^{\circ} \mathrm{C}$ por 2 minutos.

T8 - Imersão em água quente a $80^{\circ} \mathrm{C}$ por 10 minutos.

T9 - Desponte no lado oposto ao hilo.

T10 - Escarificação manual por 2 minutos.

T11 - Escarificação manual por 2 minutos seguida pela imersão em água à temperatura ambiente por 6 horas.

T12 - Escarificação manual por 2 minutos seguida pela imersão em àgua à temperatura ambiente por 12 horas

Nos tratamentos com ácido sulfúrico concentrado as sementes foram colocadas em beckers e imersas em ácido. Em seguida, foram lavadas abundantemente com água corrente. A quantidade de ácido utilizada foi o suficiente para recobrir as sementes. Os tratamentos com desponte e escarificação superficial das sementes foram feitos com o auxílio de pedra abrasiva, através do atrito superficial do tegumento, tomando-se a precaução durante a operação de controlar a intensidade e duração do processo para não danificar as partes internas da semente. $\mathrm{O}$ desponte foi aplicado em região da semente oposta ao hilo.

$O$ delineamento experimental empregado foi o de blocos casualisados com quatro repetições de 25 sementes por tratamento, totalizando 1.200 sementes. O semeio foi efetuado em agosto de 1985, utilizando-se germinador do tipo Jacobsen, em substrato de papel de filtro, à temperatura constante de $30^{\circ} \mathrm{C}$ e luz ambiente.

$\mathrm{O}$ registro da germinação foi efetuado pela contagem das sementes germinadas a cada dois dias por um período de 30 dias, quando foi encerrado o experimento. Os resultados foram avaliados em termos de porcentagem de germinação e Índice de Velocidade de Germinação (I.V.G.), calculado segundo POPINIGIS, (1977).

O I.V.G. é um índice obtido pelo número de plântulas germinadas a 
cada dia de observação, multiplicado pelo inverso do número dias decorridos após a semeadura. Os produtos diários são somados para obter o índice final.

Para fins de análise estatística, os dados de germinação foram transformados para $\mathrm{x}=$ arco seno $d a$ raiz quadrada da porcentagem de germinação. A avaliação dos dois parâmetros foi realizada através da análise de variância com Teste $\mathrm{F}$, e as médias foram comparadas pelo teste Tukey ao nível $5 \%$ de probabilidade.

\section{RESULTADOS E DISCUSSÃO}

Os tratamentos escarificadores físicos e químicos aplicados nas sementes de muirajuba favoreceram a superação da dormência em diferentes graus, quando comparados às sementes sem tratamento (TABELA 1). No tratamento testemunha (sem escarificação), as sementes apresentaram apenas $13 \%$ de germinação, com a primeira emergência ocorrendo aos 16 dias após a semeadura.

Em geral, todos os tratamentos aplicados proporcionaram uma maior emergência em relação à testemunha. Contudo os melhores resultados foram obtidos com as imersões em ácido sulfúrico, desponte do lado oposto ao hilo e escarificação manual por 2 minutos (sem e com imersão em água por 12 horas), os quais não diferiram entre sí. A aplicação de tratamentos com água fervendo, no entanto, não foi eficiente, superando apenas o tratamento testemunha (TABELA 1).
Em relação ao I.V.G., parâmetro importante para avaliar a homogeneidade e velocidade da germinação, a escarificação manual das sementes por atrito, num tempo de dois minutos, seguida da imersão em água por 12 horas, promoveu o maior índice de emergência, superior aos demais tratamentos. Estes resultados reforçam os indicativos de que o fator de dormência atuante seja a impermeabilidade do tegumento. Neste tratamento, a emergência das plântulas iniciou aos três dias após a semeadura e se prolongou por um período de 12 dias (germinação de $81 \%$ ), não apresentando novas emergências até o encerramento do ensaio. POPINIGIS (1977), afirma que a impermeabilidade do tegumento a é causa mais comum da dormência de sementes de leguminosas.

A utilização de ácido sulfúrico por diferentes períodos, também favoreceu a emergência das plântulas, com tendência de maior I.V.G. na medida em que se aumentou o tempo de imersão das sementes no ácido. $\mathrm{O}$ tratamento de desponte também produziu taxas de I.V.G. satisfatórias.

O ácido sulfúrico concentrado tem sido empregado com sucesso para quebra de dormência de sementes de várias leguminosas. Os dados obtidos por FREITAS \& CANDIDO, (1972), com guapuruvu (Schyzolobium excelsum); CARPANEZZI \& MARQUES, (1981), com jatobá (Hymenaea courbaril) e jutai $(H$. parvifolia); CANDIDO et al., (1982), com timbaúva (Enterolobium 
contortisiliquum); VARELA et al., (1986/87), com faveira-arara-tucupi (Parkia decussata); VARELA et al., (1991), com faveira-camuzé (Sthyphnodendron pulcherrimum), e outros, constataram a eficiência do uso de ácido sulfúrico na superação da dormência de sementes destas espécies. Vale ressaltar que tal prática exige cuidados e é de difícil acesso para muitos produtores rurais.

Os tratamentos que envolveram a escarificação superficial do tegumento das sementes por dois minutos, as quais posteriormente foram imersas em água à temperatura ambiente, por diferentes tempos (sem imersão, 6 e 12 horas), não apresentaram um comportamento linear. Após a escarificação manual, 6 horas de imersão em água não apresentou resultados intermediários para germinação e I.V.G. entre 0 e 12 horas de imersão em água, como se esperava. Os dados obtidos para 6 horas de imersão foram inferiores aos do tratamento sem imersão em água, que por sua vez foram menores que com 12 horas de imersão. Um dos fatores que podem ter influenciado neste comportamento pode ter sido o conteúdo adequado de umidade no germinador que permitiu rápida embebição de sementes que não foram imersas em água.

Esses resultados sugerem um melhor estudo acerca da intensidade $\mathrm{e}$ da duração do processo de escarificação da superfície do tegumento de sementes de muirajuba em pedra abrasiva, bem como do período de imersão das sementes em água antes da semeadura. É importante também que tratamentos mecânicos não causem danos ao embrião. TORRES, (1983), constatou efeitos positivos da imersão em água na germinação de sementes não escarificadas de muirajuba. VARELA et al., (1991), efetuaram escarificação manual seguida de imersão em água por seis horas em faveira-camuzé e a aplicação deste tratamento proporcionou uma alta taxa de emergência das plântulas.

A imersão em água à temperatura de $80^{\prime \prime} \mathrm{C}$ por 2 e 10 minutos não apresentou resultados satisfatórios na quebra da dormência, sendo a porcentagem de germinação para os dois tratamentos inferior a 50\%, embora estatisticamente superiores a testemunha. Estes tratamentos não apresentaram diferenças significativas nos valores de I.V.G. em relação aos obtidos com a testemunha. $\mathrm{O}$ efeito do uso de água quente na superação da dormência de sementes é uma função do tempo de imersão, e tem uso frequente com leguminosas. Para CARNEIRO, (1968), o efeito favorável da água fervendo sobre as sementes de leguminosas é atribuido à ação da temperatura sobre a cutícula cerosa das células paliçadicas que compõem o tegumento das sementes. Nos níveis aplicados neste experimento, não houve resultados positivos para uso de água aquecida na superação da dormência das sementes de muirajuba. Os períodos de exposição à água quente utilizados aqui foram de média intensidade e é possível que não tenham provocado danos na 
casca, passo indispensável para embebição de sementes que apresentam dormência causada pelo tegumento impermeável. Estes resultados concordam com TORRES, (1983), que trataram sementes de muirajuba com água quente, mas não verificaram germinação eficiente.

Para a acácia negra (Acacia mearnsii), ABRÃO \& DIAS (1978), recomendam a imersão das sementes em água fervendo por 10 minutos como imprescindível para obter boa germinação da espécie. BIANCHETTI \& RAMOS (1981a), obtiveram percentuais de germinação ótima quando colocaram sementes de Schizolobium parahyba em água fervente por intervalos de 4-10 minutos. Contrariamente, outros autores com diferentes espécies de leguminosas não obtiveram efeitos satisfatórios na superação da dormência quando submeteram as sementes a tratamentos com àgua quente (BIANCHETTI \& RAMOS, 1981b;CARPANEZZI \& MARQUES, 1981; CANDIDO et al., 1982).

CARPANEZZI \& MARQUES (1981), alertam que o uso de ácido é um método caro e recomendado apenas em situações em que envolvam um número reduzido de sementes, e/ou em que seja necessário maximizar a porcentagem de germinação. Como alternativa, os resultados experimentais aqui obtidos identificaram que os tratamentos de desponte do lado oposto ao hilo, e escarificação manual com imersão em água por 12 horas, que não diferiram da maioria dos tratamentos com ácido, nos parâmetros avaliados, e podem também ser utilizados como escarificadores das sementes de muirajuba.

\section{CONCLUSÕES}

1. A germinação de sementes não escarificadas de muirajuba foi de $13 \%$. A baixa germinação foi atribuída à dormência devido a impermeabilidade do tegumento.

2. A aplicação de diferentes tratamentos escarificadores favoreceu a germinação da muirajuba em diferentes graus. As sementes tratadas com desponte do lado oposto ao hilo, imersas em ácido sulfúrico por períodos de 5, 10 , 15,20 e 30 minutos, e escarificadas mecânicamente sem e com imersão em água por 12 horas, proporcionaram alta germinação e encurtaram o tempo de emergência das plantas.

3. A escarificação mecânica manual do tegumento por dois minutos em pedra abrasiva com posterior imersão em água por 12 horas, proporcionou o maior índice de vigor dentre os tratamentos testados.

4. Os tratamentos onde se avaliou a imersão das sementes por dois e dez minutos em água quente $\left(80^{\circ} \mathrm{C}\right)$, não foram eficientes para obtenção de germinação homogênea da muirajuba.

5. Embora os tratamentos usados não tenham sido de máxima eficiência para um expressão de $100 \%$ da germinação das sementes, considera-se que os tratamentos de desponte e os de imersão em ácido sulfúrico são altamente promissores e recomendáveis como métodos para superação da dormência de sementes de muirajuba. 
Tabela 1. Efeitos de tratamentos pré-germinativos na porcentagem e velocidade da germinação de sementes de muirajuba (Apuleia leiocarpa (Vog.) Macbrid var. molaris (Spr.) ex Benth.). *I

\begin{tabular}{lccc}
\hline \multicolumn{1}{c}{ Tratamentos } & $\begin{array}{c}\text { Germinação ("2) } \\
(\%)\end{array}$ & $\begin{array}{c}\text { Índice de } \\
\text { Velocidade de } \\
\text { Germinação } \\
\text { (I.VG.) }\end{array}$ & $\begin{array}{c}\text { Primeira } \\
\text { emergência (dias } \\
\text { após a } \\
\text { semeadura) }\end{array}$ \\
\hline Testemunha & $13 \mathrm{~d}$ & $0,14 \mathrm{~d}$ & 16 \\
Ácido sulfúrico por $5 \mathrm{~m}$ & $76 \mathrm{ab}$ & $2,22 \mathrm{c}$ & 5 \\
Ácido sulfúrico por $10 \mathrm{~m}$ & $82 \mathrm{a}$ & $2,34 \mathrm{bc}$ & 5 \\
Ácido sulfúrico por $15 \mathrm{~m}$ & $82 \mathrm{a}$ & $2,52 \mathrm{bc}$ & 5 \\
Ácido sulfúrico por $20 \mathrm{~m}$ & $76 \mathrm{ab}$ & $2,46 \mathrm{bc}$ & 5 \\
Ácido sulfúrico por $30 \mathrm{~m}$ & $80 \mathrm{a}$ & $3,04 \mathrm{bc}$ & 4 \\
Água a $80^{\circ} \mathrm{C}$ por $2 \mathrm{~m}$ & $55 \mathrm{bc}$ & $0,72 \mathrm{~d}$ & 9 \\
Água a $80^{\circ} \mathrm{C}$ por $10 \mathrm{~m}$ & $46 \mathrm{c}$ & $0,82 \mathrm{~d}$ & 7 \\
Desponde oposto ao hilo & $85 \mathrm{a}$ & $2,88 \mathrm{bc}$ & 5 \\
Escarific. manual por $2 \mathrm{~m}$ & $66 \mathrm{abc}$ & $3,22 \mathrm{~b}$ & 4 \\
Esc.man./2 m, 6hs imersão & $48 \mathrm{c}$ & $2,18 \mathrm{c}$ & 4 \\
Esc.man/2 m, 12hs imersão & $81 \mathrm{a}$ & $4,99 \mathrm{a}$ & 3 \\
Coeficiente de variação (\%) & 10,96 & 17,46 & - \\
\hline
\end{tabular}

- 1 - Médias seguidas de mesma letra em cada coluna, nâo diferem estatisticamente entre si pelo teste de Tukey $(P>0,05)$.

-2 - $\mathrm{Na}$ análise de variância os valores foram transformados em arco seno da raiz quadrada de $\mathrm{x}$.

\section{Bibliografia citada}

ABRĀO, P.V.R.; DIAS, C.A. 1978. Tratamentos pré-germinativo em em sementes de Acácia Negra (Acacia mearnsii De Willd). Roessleria, Porto Alegre, v. 2, p. 57-68.

ALLEN, O.N.; ALLEN, E.K. 1981. The leguminosae, a source book of characteristics, uses, and nodulation. Madison, Univ. de Wisconsin Press, 58-59.

BIANCHETTI, A.; RAMOS, A. 1981a. Quebra de dormência de sementes de guapuruvu (Schizolobium parahyba (Velloso) Blake). Bol. de Pesq. Flor, Curitiba, 3: 69-76.

BIANCHETTI, A.; RAMOS, A. 1981b. Quebra de dormência de sementes de canafistula
(Peltophorum dubium Spreng) Taubert. Resultados preliminares. Boletim Pesq. Flor, Curitiba, 3: 87-95.

CÂNDIDO, J.F.; SILVA, R.F; CONOE, A.R.; LEDO, A.A.M. 1982. Orelha de negro (Enterolobium contortisiliquum (Vell.) Morong: dormência e métodos para a sua quebra, Rev. árvore, Viçosa, 6 (2): 104 110.

CARNEIRO, J.G.A. 1968. Métodos para quebra de dormência de sementes. Rev. Floresta, 6 (II): $24-30$.

CARPANEZZI, A.A.; MARQUES, L.C.T. 1981. Germinação de sementes de jutai-açu (Hymenaea courbaril L.) e jutai-mirim (H. parvifolia Huber) escarificadas 
com ácido sulfúrico comercial. Belém, EMBRAPA, CPATU, Cir. Tecn., 19, 15p.

FARIA, S.M.; FRANCO, A.A.; JESUS, R.M.;MENANDRO, M.S.; BAITELLO, J.B.; MUCCI, E.S.F.; DOBEREINER, J.; SPRENT, J.I. 1984. New nodulating legume trees from south-east Brazil. New Phytol., 98: 317-328.

FREITAS, A.R.; CHIMELO, J.P. 1982. Utilização de madeiras amazônicas para a produção de dormentes para o projeto ferro Carajás. In: Silvicultura em São Paulo, Anais do Congr. Nac, sobre ess, nativas, Campos do Jordão, v. 16:1316-1317.

FREITAS, J.A.C.; CÂNDIDO, J.F. 1972. Tratamento químico para abreviar a germinação de sementes de guapuruvu (Schyzolobium excelsum Vog.) e de mamoeira (Tachigalia multijuga Bth.). Seiva, Viçosa, (32): 1-10.

FROES, R.L. 1959. Informaçōes sobre algumas plantas econômicas do planalto amazônico. Bol. Tecn. do IAN, $\mathrm{n}^{\circ}$ 35, Belém, $113 \mathrm{p}$.

LEITE, E.J.; HAY, J.D. 1989. Regeneração natural de garapa, Apuleia leiocarpa (Vog) Macbr. numa reserva genética.Ciência e Cultura, SBPC, 41(8):804807.

LELLES, J.G.; REIS, M.S.; VALENTE, O.F.; SOUZA, A.P. 1978. Durabilidade de moiroes preservados em condiçóes de campo, Rev, da Arvore, Viçosa, 2(1); 27-33.

LOUREIRO, A.A.; LISBOA, P.L.B. 1979. Madeiras do município de Aripuanä e suas utilidades (Mato Grosso). Acta Amazônica, Suplemento $\mathrm{N}^{\circ} 1,88 \mathrm{p}$.

MAGALHÃES, L.M.S.; SOUZA, L.A.G.; GOLDMAN, G.H.; GOLDMAN, M.H.S. 1985. Relatório final do projeto de preservação do germoplasma do reservatório da UHE-Tucuruí. Convênio ELETRONORTE/CNPq/INPA, Manaus, 53p.

PAULA, J.E. 1982. Espécies nativas com perspectivas energéticas. Silvicultura em São Paulo. Anais do Congresso Nac: sobre essências nativas, IF, Campos do Jordão, $1259-1262$
POPINIGIS, F. 1977. Fisiologia da semente. Brasilia, AGIPLAN, 289p.

REVILLA, J.C.; KAHN, F.L.; GUILLAUMET, K.L. 1982. Relatório semestral do INPA. Convênio ELETRONORTE/CNPq/INPA, Manaus, 50p.

RIZZINI, C. 1971. Árvores e madeiras úteis do Brasil. Manual de dendrologia brasileira. São Paulo, Edgard Blucher LTDA, USP, $294 \mathrm{p}$.

RIZZINI, C.T.; MORS, W.B. 1976. Botânica econômica Brasileira. USP, São Paulo, pg 123.

SOUZA, J.M.A. 1987. Caracterizą̧ão éndices qualificativos de 20 espécies florestais do Acre. Rio Branco, AC, Secret. de Industr. e Comerc., 124p.

SUDAM/IPT, 1981. Grupamento de espécies tropicais da Amazônia por similaridade de características básicas e por utilização. Belém, SUDAM, 237p.

TORRES, M.A.V. 1983. Técnicas silviculturais em espécies nativas. In: A silvicultura de espécies nativas. FUPEF, Curitiba, 56p.

VARELA, V.P.; AQUINO, P.A.; AZEVEDO, C.P. 1986/87. Tratamentos pré-germinativos em sementes de especies florestais da amazônia. III. Faveira arara tucupi (Parkia decussata). Acta Amazônica, 16/17: 557562.

VARELA, V.P;; BROCKI, E.; SÁ, S.T.V. 1991. Tratamentos pré-germinativos de sementes de espécies florestais da amazônia. IV. Faveira camuzé (Stryphnodendron pulchenimum). Rev Brasileira de sementes, 13 (2): 87-90.

VENTURIERI,G.A.; CORADIN, L;; LLERAS, E.; MAGALHÃES,L.M.S.; SOUZA. L. A. G . ; C LE M E N T, C. R .; MACHADO,G.M.E; GOLDMAN,G.H. 1984. Metodologia aplicada na coleta de germoplasma de espécies florestais e frutíferas que ocorrem na área de influência da barragem de Tucuruí-PA, Brasil. Anais do Simp. Internac. sobre mét de prod e contr: de qual. de sem. e mudas florestais, Curitiba, 29-39. 